\title{
La tecnópolis en España
}

\author{
Josep Maria Cortés \\ Universitat de Barcelona \\ josepmcortesmarti@ub.edu \\ Ignasi Brunet \\ Universitat Rovira i Virgili \\ ignasi.brunet@urv.cat
}

Resumen: El objetivo de este artículo es exponer el método que se ha empleado en una investigación realizada, y que ha permitido recuperar unas "piezas» esenciales de nuestra arqueología industrial, posibilitándonos la reconstrucción de la tecnópolis en España, la cual se inscribió en el pensamiento organizativo de principios del siglo $X X$ y cristalizó posteriormente en un modelo de sociedad fundamentada en una mayoría selecta. Ello tuvo que ver con la implantación de la producción en masa que, como institución técnico-organizativa e instrumento de control del proceso productivo, provocó la formación de una clase media trabajadora, poseedora de capital cognitivo técnico, y convertida en pequeña propietaria de bienes obtenidos mediante el mercado de consumo de masas.

Palabras clave: tecnópolis, disrupción, tecnología, ilusión organizativa, sképsis.

\section{The technopolis in Spain}

Abstract: The objective of this article is to describe the method used in research that has recovered certain essential "pieces" of our industrial archaeology, thus enabling the reconstruction of the Technopolis in Spain, which was prominent in the organizational thought of the early twentieth century and later became crystallized in a society model based on a selected majority. This had to do with the implementation of mass production that, as a technical-organizational institution and instrument of control of the productive process, caused the formation of a working middle class who possessed technical cognitive capital and turned into small owners of goods obtained through the mass consumer market.

Keywords: Technopolis, disruption, technology, organizational illusion, Sképsis. 


\section{Introducción}

La configuración teórica del modelo fordista en España discurrirá en torno a debates teóricos técnico-organizativos cuyo discurso resultante fue el pensamiento organizativo, que propondrá un modelo de sociedad fundamentada en una mayoría selecta, caracterizada por su capacidad de proyecto y novación en relación con la industrialización, en la manufactura de bienes materiales, y en el poder de la máquina y la fábrica. El pensamiento organizativo tuvo como objeto el análisis crítico y subsiguientemente adaptación en la factoría de la organización científica del trabajo, con el objetivo de proponer un modelo de sociedad centrada en los criterios de productividad para alcanzar una distribución de la riqueza más equitativa, pero plagado de valores proempresariales. Ello supondrá idealizar el trabajo industrial como la forma normativa de producción social, y convertir el salario industrial en herramienta mediante la que se gobierna a la población, y dejar de reivindicar a la clase obrera como sujeto para la transformación del capitalismo, y optar también por el concepto neoclásico de consumo, es decir, por una democracia de consumo, que, según Baudrillard (2010: 45), es, más bien, una institución y una moral y, por tal, un concepto, «un elemento de la estrategia del poder» en toda sociedad constituida o por venir.

Baudrillard (2012: 85) planteaba que el adiestramiento actual «para el consumo sistemático y organizado es el equivalente y la prolongación en el siglo $\mathrm{xx}$ del gran adiestramiento en el sector del consumo a que fueron sometidas las poblaciones rurales a lo largo de todo el siglo xix para adaptarse al trabajo industrial. El mismo proceso de racionalización de las fuerzas productivas que tuvo lugar en el siglo Xix en el sector de la producción se consuma en el siglo XX». Y es que el sistema industrial, una vez que hubo socializado, mediante las relaciones salariales, a las masas como fuerza de trabajo, «debía avanzar aún más para consumarse y socializarlas (es decir, controlarlas) como fuerzas de consumo». El individuo como fuerza de consumo se convierte en un nuevo siervo, lo que permite a Baudrillard (2012: 87) definir el «consumo no solo estructuralmente como sistema de intercambio y de signos, sino estratégicamente como mecanismo de poder».

En este sentido, el concepto de tecnópolis del pensamiento organizativo en España evidencia una propuesta en la que, apoyándonos en Baudrillard (2012: 86), «la producción y el consumo constituyen un único y gran proceso lógico de reproducción ampliada de las fuerzas productivas y de su control». El eje de lo social en la tecnópolis pasa por una estructura social producida por la organización científica del trabajo, pero sometida a su vez a la lógica del consumo, y en la que no se reconoce la «importancia estratégica que tiene la esfera de actividades y relaciones mediante las cuales se reproducen nuestras vidas y la fuerza de trabajo, 
tanto para el desarrollo del capitalismo como para la lucha contra él, empezando por la sexualidad, la procreación y, por encima de todo, el trabajo doméstico no remunerado de las mujeres» (Federici, 2018: 48).

Como indica Aglietta (1979: 94 y 131), «el principio de una articulación del proceso de producción y del modo de consumo que instaura la producción en masa resultará ser clave para la universalización del trabajo asalariado», y la reproducción de las jerarquías de género. De hecho, en el régimen fordista como en la tecnópolis española los trabajadores se verán forzosamente atados al capitalismo, por un lado, «por el consumo individual de mercancías resultantes de la producción en masa. Ese modo de consumo uniforme de productos trivializados es un consumo de masas». Por otro, por la familia nuclear, cuya glorificación como «ámbito privado» es la esencia de la ideología capitalista, que contrapone la «familia (o la comunidad) a la fábrica, lo personal a lo social, lo privado a lo público, el trabajo productivo al improductivo». Esta ideología es «útil de cara a nuestra esclavitud en el hogar que, en ausencia de salario, siempre ha aparecido como si se tratase de un acto de amor. Esta ideología está profundamente enraizada en la división capitalista del trabajo que encuentra una de sus expresiones más claras en la organización de la familia nuclear» (Federici, 2018: 38), otra forma de organización científica del trabajo, en la que, como nos relata Bauman (2000), en ambas formas de organización, el trabajo irá perdiendo su función de principio regulador cediendo lugar a la iniciativa del consumidor.

Con ello, con la descomposición de las formas sociales propias de la modernidad «sólida», se entrará en un nuevo escenario «líquido», posfordista o neofordista (Brunet y Bocker, 2013). Un nuevo escenario, «una segunda modernidad», en la que ser consumidor es la primera obligación en esta nueva comunidad de consumidores en que se ha transformado la sociedad de productores fordista. Una nueva comunidad en la que el elemento integrador va a ser la estética y no la ética. En palabras de Bauman (2000: 56), «la estética del consumo gobierna hoy, allí donde antes lo hacía la ética del trabajo», y es que la élite actual considera toda forma de trabajo como una cuestión de satisfacción estética. Por ello, uno de los cambios más llamativos de las sociedades de consumo actuales remite a la noción de creatividad y de innovación, y que son los ejes del discurso del nuevo management, discurso y nuevo espíritu del capitalismo (Boltanski y Chiapello, 2002; Sassen, 2007; Sánchez Capdequí, 2017).

El artículo se estructura en descripción metodológica, análisis conceptual y conclusión. En primer lugar, en «Reivindicación de la investigación artesanal» se reflexiona sobre el método en las ciencias sociales y se describe el proceso metodológico que fue utilizado. En segundo lugar, en «Conceptos y definiciones» 
se exponen las perspectivas terminológicas con especial atención al concepto de «tecnópolis»y su relación con el término «disrupción». Seguidamente, se analiza el «texto en su contexto» con una perspectiva diacrónica del marco de referencia definiendo los cuatro vértices significativos: en primer lugar, la ennoia ("̌vvoı que se traduce como autoimagen de la mayoría, que un día fue selecta como efecto del proceso organizativo, y cuyo objetivo fue afianzar el retorno de las inversio-

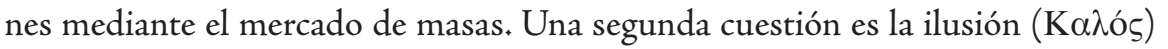
de equidad gracias a la posibilidad de acceder a un consumo de bienes cuya simbología definió la clase trabajadora como clase media, es decir, una mayoría selecta por su capacidad de consumo, y como efecto directo de la implantación de la producción en cadena. Un tercer vértice del marco de referencia es aquello que fue (Aó@ıбтs); una sociedad que se autodefinió como modelo social a imitar, en que la combinación entre un capitalismo organizado y los Estados de bienestar estructuró una sociedad autosatisfecha. Y el cuarto vértice (Елохи́) es el presente cuya perspectiva de incertidumbre y precariedad es el resultado directo de la desregulación de los mercados financieros y el desmantelamiento del Estado de bienestar. Finalmente, en la conclusión se analizan los conceptos resultantes del pensamiento organizativo español y de su modelo de sociedad: la tecnópolis española.

\section{Reivindicación de la investigación artesanal}

\subsection{La mirada del socioeconomista}

Los socioeconomistas para la interpretación del fenómeno socioeconómico recurrimos a las herramientas de la sociología organizativa, pero con la perspectiva de la historia económica más reciente. Metodología que nos remite a conceptos de institución y de reproducción social, y que nos permite una visión ideográfica a la vez que comprehensiva de la innovación social. Es decir, esta metodología recurre a la interpretación del devenir diacrónico de la historia y a los conceptos sincrónicos de la sociología. No es un enfoque de un economista tradicional. Pero tampoco el de un sociólogo en su acepción más común. Al respecto, Sampedro (2009) distingue tres tipos de economistas. El primero, aquellos que trabajan en la cuantificación de la unidad monetaria utilizando el instrumental marginalista de la misma forma que lo utiliza un físico para analizar el movimiento, describiendo variables abstractas del «espacio euclidiano» para explicar el fenómeno económico. Dicha perspectiva analítica excluye la naturaleza no solo de su dimensión social sino de su potencialidad psicológica, intrínseca en el mismo fenómeno económico. Ámbitos de realidad social que excluye por considerarlos 
excesivamente interpretativos, ya que el algoritmo matemático por sí mismo se autointerpreta como objetivo y a la vez científico (Ibáñez, 1985; Lamo de Espinosa, 1990; Brunet y Pastor, 2003).

Un segundo tipo de economistas son aquellos que tienen la necesidad de entender el fenómeno económico utilizando las herramientas analíticas que ofrece la historia y el marco de referencia sociológico. Dicha perspectiva nos lleva a los conceptos de institución y reproducción para llegar a la comprehensión del fenómeno económico estudiado, incluso recurriendo en las interpretaciones de la psicología social. Los economistas institucionalistas precisan del marco de referencia para interpretar y explicar que las transformaciones económicas son comprensibles en tanto que sociales a la vez que humanas, mirada metodológica que nos acerca a la Geisteswissenschaften de Wilhelm Dilthey (1833-1911).

Por último, aquellos economistas que se encuentran en la necesidad de explicar los cambios no solo haciendo uso de las disciplinas antes mencionadas, sino explicaciones de largo recorrido que se dividen en cambios de modelo político como efecto directo del cambio estructural de las relaciones de producción. Planteamiento que incide en la importancia de la evolución tecnológica y de la transformación del marco institucional como efecto de las relaciones sociales, de por sí complejas, de los seres humanos en su dialéctica en el devenir histórico entre hombres y circunstancias productivas; circunstancias que afectan en el modo de cómo se ordena la prelación del poder y la articulación del modelo político consecuente, tal como expuso el marxismo tradicional en su día. Los economistas que utilizamos el instrumental sociológico sabemos que las grandes transformaciones de la sociedad - cambio social en la sociología - no tienen cabida y, por lo tanto, no se plantea, en la economía marginalista/financiera; postura epistemológica que, a pesar de la supuesta objetividad de su planteamiento, no excluye una postura ideológica, con el objetivo de inocular un autismo social que incapacita la comprensión de las relaciones de poder.

\subsection{Una investigación artesana}

La investigación que se llevó a cabo se afanó en explicar el cambio social a la vez que económico por la aplicación de una tecnología que pasó desapercibida, por cotidiana y por fugaz, que sirviéndose de la terminología recientemente incorporada en el lenguaje habitual podríamos denominar soft. Es decir, no mediante una tecnología visible y palpable, física en cierta medida o hard, utilizando estos términos ya normalizados en nuestro acervo lingüístico. Sino, más bien, una tecnología etérea, de carácter gaseoso, borroso, difícil de palpar y visualizar a simple vista. En este sentido, tecnópolis deshilvana la trama y la urdimbre de aquel tejido 
industrialista cuya propuesta se motorizó con la arquitectura taylorista-fordizadora de la organización del trabajo, que de una manera más o menos definitoria se nombró organización científica del trabajo, cuyo acrónimo (OCT) hizo fortuna en ambientes académicos y en los manuales de sociología del trabajo de una época no demasiado lejana. Cuyo objetivo fue la reconstrucción de un discurso que profesa la investigación artesana, de manera que, como arqueólogo de la industria reciente, aunque parezca discordante la temporalidad, desempolvamos con espátula su contextura para cincelar la arquitectura de su modelo social.

Por consiguiente, tecnópolis desenterró un discurso sobre pensamiento organizativo y su mayoría selecta, dejando al descubierto el impacto de las innovaciones organizativas, las cuales fueron ocultadas por el gran empuje de las innovaciones tecnológicas de carácter mecánico-físico. El trabajo de investigación efectuado ambicionó hacer visible aquello que en su día el susodicho hermeneuta alemán denominó fenómenos ideográficos en relación con su naturaleza estrictamente social, la cual solo tiene cabida en los complejos fenómenos de la construcción de la realidad, que, sin la intención de ser reiterativo, es profundamente social, colectiva. El decurso analítico se dividió en dos intervalos temporales: pensamiento organizativo de 1900-1936, siendo la etapa más significativa discursivamente hablando; y la mayoría selecta, 1940-1980, como expresión más definitoria de su modelo social, que sin duda articuló el capitalismo organizado español. Dicho de otra manera, aludimos a los conceptos de la socioeconomía de una etapa esencial que recorrió el modelo social de capitalismo organizado en España.

En consecuencia, desbrozamos los efectos del pensamiento organizativo como ámbito significativo que nos permitió la interpretación de largo recorrido de la mayoría selecta. Sintetizando en dos puntos, podemos afirmar:

- El pensamiento organizativo de nuestra tecnópolis se escenificó muy a finales del siglo xix y la primera tercera parte del siglo xx. Y como eje de una puerta rotatoria, se elaboró de forma espontánea, y con un cierto carácter diletante, por parte de aquellos autores que participaron y escribieron sobre la temática. Su difusión, aunque tenue en los ambientes fabriles de la época, estuvo recluida básicamente entre las paredes de la academia, aunque ello no fue óbice para que se produjera en un lapso de unos treinta años una literatura sobre el taylorismo y el fordismo de un cierto grosor, e incluso en algunos de los casos de una cierta apología fuese a favor o fuese en contra.

- La mayoría selecta de tecnópolis describe un cambio social a la vez que económico mediante la aplicación de esa tecnología soft. Pues es con dicha perspectiva - aquello que en nuestro gremio sociológico bautizamos con 
cierta erudición, pero a la vez con cierta ironía de «mirada sociológica»se reconstruye su arquitectura, consecuencia de la aplicación intensiva de la OCT. Cuyo efecto latente fue su capacidad de encabezar el proyecto de modernización bajo criterios organizativos tayloristas exhibiendo el modelo social que instituyó el fordismo.

\subsection{Método arqueológico documental en la sociología de las organizaciones}

El método sociológico hace algún tiempo se movía en la dicotomía cuantitativocualitativo. Es probable que la cantidad llevara implícitos aspectos tan valorados como la precisión. En cambio, el análisis cualitativo parecía ser que nos llevara por derroteros de ambigüedad. El significado de la palabra es por regla general poco concreto. En tanto al número se le atribuye un gobierno riguroso, a la palabra se le otorga una imprecisión inherente. Sin embargo, para la sociología números y palabras son algo más que sistemas de registro. La sociología como ciencia es algo peculiar, al menos hasta ahora, no sé si a partir de la irrupción de las nuevas tecnologías se convertirá en la física social que aspiraba Comte. De momento, el trabajo efectuado no pretendía descubrir las unidades de medida de la nounata sociometría. En todo caso, toma la palabra y el número como datos significativos de contexto. Es decir, el texto acompañado por un viaje significativo de hechos constituyendo el marco de referencia, término que habitualmente usamos los sociólogos para referirnos a aquello que acontece en el momento o aquel momento, como fragmentos arqueológicos de una arquitectura significativa (Vallés, 1996; Babbie, 2000; Corbetta, 2003; Ruíz Olabuenaga, 1996; Weber, 1981).

La labor realizada para desempolvar los textos (sea opúsculo, libro, artículo, revista, sea o no especializada) es más similar a la de un arqueólogo con salacot, que, sin serlo, se esfuerza en realizar un trabajo de redescubrimiento. La metodología es un lento proceso de búsqueda, vaciado, comprensión y explicación de los contenidos que versan sobre la temática. En cierta medida el proceso de trabajo se asimila a como lo definen los metodólogos de arqueología documental, entendida como una manera de trabajar para encontrar aquellos textos, ya olvidados, que pertenecen a espacios, tiempos, géneros y plumas varios que modelan un sujeto discursivo que se circunscriben en una temporalidad pretérita. Sin embargo, hay que decir que hoy la arqueología no busca el coleccionismo, sino que pretende el conocimiento del pasado, aunque sea muy cercano, a través de todos los restos materiales y las diversas simbologías.

En el simple hecho de elegir un método de investigación u otro es importante tener en cuenta algunas consideraciones, aunque siendo repetidas hasta la sacie- 
dad en los manuales de las mal denominadas ciencias sociales, no es baladí insistir en ello para ser conscientes y a la vez cautos de que los paradigmas metodológicos de por sí dominantes no constituyen una garantía de veracidad, ni la herramienta que nos permita alcanzar la objetividad de por sí utópica. Con ello no se pretende justificar si el presente trabajo cumple o no la supuesta imparcialidad. Tampoco es nuestra ambición. No se reivindica contraponer las ciencias duras, de por sí explicativas, con las ciencias humanas, por naturaleza comprensivas. El trabajo metodológico efectuado aspira tener un aire profesoral y pedagógico, aunque signifique distanciarse del apelativo científico, sabiendo de antemano que dicha actitud analítica en relación con cierto discurso académico obligado al impacto puede quedar infravalorada, aunque en realidad no sea del todo así. A veces ocurre que la ambición de aplicar un método considerado el más idóneo puede distorsionar el objeto y a priori ninguno de ellos puede ser considerado como mejor.

Además, el método considerado como el mejor puede ser enemigo de lo bueno y el ansia de perfeccionismo puede provocar un análisis esterilizante. Las exigencias de contexto de la investigación son un factor decisivo a considerar en la elección de los métodos, por este motivo principalmente, el método cualitativo documental ha sido el más apropiado para atender la necesidad del objeto. A pesar de que no hay una sola metodología concreta, ni un solo tipo de técnicas, ni siquiera un solo instrumento, para la elaboración de cualquier trabajo con ambición académica. Dada la naturaleza del objeto de análisis, lo que se propone es una explicación comprensiva de una realidad social y, por lo tanto, relativamente próxima, en que el acercamiento archivístico a la vez que arqueológico como soporte documental ha proporcionado un enriquecimiento sistemático de interpretación, descifrando pacientemente documentos, muchos de ellos inéditos, concienzudamente seleccionados, ponderadamente clasificados y sociológicamente comprendidos.

Por otro lado, nuestro interés se circunscribe, aunque no únicamente, en poner al descubierto un relato que surgió en el primer amanecer del novecientos de distintos autores de ámbitos académicos diversos, que aprovecharon la coyuntura de la novación que significó el taylorismo en un primer momento y el fordismo posteriormente para proponer un modelo social acorde, fuera a favor o en contra, de la nueva tecnología organizativa. De hecho, el pensamiento organizativo español propone modelos sociales que ambicionan una nueva estructura social de nuestra sociedad en los albores del siglo xx. Otro aspecto, más de perspectiva y manera de definir la temporalidad sociológicamente hablando, es el eje pasado inmediato y presente continuo, como herramienta argumentativa que nos permite esa visión de largo recorrido de cómo el pasado ejerce presión en el presente, abordando una 
interpretación muy sugerente de nuestra reciente sociedad industrial mediante el discurso organizativo. Sin embargo, la labor de interpretación documental en su literalidad conlleva que su potencial significativo no puede trascenderse a sí mismo, y que, por lo tanto, quede anclado en su tiempo, un tiempo anterior al nuestro, y sea dependiente de él. Ahora bien, por el contrario, cuando a la memoria documental se le da un significado ejemplarizante, el contenido se constituye en modelo, posibilitándonos la comprensión de realidades sociales presentes, por lo que el tiempo pasado se encuentra subsumido en el tiempo presente sirviéndonos como guía de acción con la intencionalidad de sonsacar lecciones de por sí magistrales.

Por otro lado, la arqueología industrial aporta un instrumental analítico del pasado históricamente cercano, casi sociológico, a través del estudio de las instituciones industriales mediante restos físicos que presuponen una abstracción simbólica altamente significativa que permite delimitar el marco de referencia valorativo. Época caracterizada no solo por los productos técnicos elaborados en masa, sino por la organización de procesos fabriles, caracterizada por su simplificación con el objetivo de disminuir hasta el máximo el coste por unidad fabricada. Teniendo presente de antemano que fue el medio, no el fin, ya que la finalidad última de aquel modelo de sociedad fue alcanzar el máximo beneficio en mercados administrados o competitivos.

Por consiguiente, el trabajo realizado y que exponemos se puede concebir como una labor a la vez que ejercicio de arqueología documental que atañe a un tiempo inmediatamente anterior al nuestro, cuyas implicaciones son todavía sociológicas. Para desarrollar la investigación efectuada ha sido necesario consultar una extensa gama de documentos cuya estrategia se ha fundamentado en el estudio de medios para obtenerlos y análisis de presentación en relación con el formato original. El tratamiento documental consta de cuatro etapas. La primera, selección y sistematización; la segunda, vaciado y clasificación, y la tercera, interpretación y explicación. La cuarta, como conclusiva, es caracterizada por una labor minuciosa de exposición que no debe comportar una distorsión significativa de la misma.

Otro aspecto, no menor, es el nuevo escenario neofordista o posfordista que suponen las nuevas tecnologías de la información y la comunicación, conocidas con el acrónimo de TIC, obligando al analista a incorporarlas como herramientas al proceso de investigación, analizando los medios más adecuados para obtenerla. Las nuevas tecnologías juegan un papel primordial, permitiendo un sistema conexionado que nos proporciona colateralmente documentos de diversa índole que deben de ser previamente seleccionados y revisados antes de incorporarlos 
como material de investigación, ya que los criterios de clasificación y las modalidades de almacenamiento van más allá de los tradicionales criterios de biblioteconomía y documentación. Aparte de la velocidad de disposición, la virtualización nos permite un acceso documental a material antes de difícil consulta, siendo imprescindible para la tarea investigadora emplear dichas herramientas como nueva técnica de acceso a fuentes de diversa índole, sean bibliográficas o videográficas, cuyo espacio virtualizado permite llegar a documentación internacional antes difícilmente localizable.

Actualmente, la presencia del instrumental informático y de las TIC posibilita mucha más velocidad en el proceso de búsqueda del material, aunque ello no debe ser la excusa ni debe sustituir el trabajo «artesanal» de adobar el ámbito a estudiar formado por la labor de indagación, consulta, observación, experiencia, interpretación, exposición y, finalmente, la lección resultante. Pautas todas ellas que forman parte sustancial del quehacer investigador tradicional y que no pueden ser sustituidas ni absorbidas por el nuevo ímpetu tecnológico, convirtiéndose, algunas de las veces, en sujeto en lugar de objeto, e incluso pueden diluir la finalidad del propio análisis. Aunque debemos reconocer a los que pertenecemos a las generaciones analógicas que las nuevas tecnologías de consulta y documentación nos transportan a destino de manera más rápida y cómoda, hecho que se agradece, ya que el trasiego de búsqueda documental se asemejaba más a una pasión cinegética, husmeando la presa entre archivos y estanterías, biblioteca por biblioteca. Hoy la tarea investigadora pasea por conexiones de fibra óptica, como en su día las ideas recorrían caminos de tinta y letra impresa, aunque a pesar de los avances realmente imponentes de la virtualidad, el bit anida finalmente entre letra y papel, pero sobre todo en la actitud de mirar, observar y considerar la realidad social como objeto; es decir, todo un ejercicio de Sképsis.

\section{Conceptos y definiciones}

\subsection{Cuestiones conceptuales desarrolladas}

Definir lo que se entiende por pensamiento - acto de pensar y de expresarlo de forma ordenada - no es tarea fácil, pues cabe multitud de acepciones, que según se defina puede orientar el relato. Por pensamiento, entendemos aquellas formas complejas de comprender el mundo con una actitud más bien propositiva. Las formas de pensar, lo que en ámbitos de la economía denominamos instituciones de pensamiento económico, comparten, como no puede ser de otro modo, una mirada sociológica. El fenómeno que nos atañe, el pensamiento organizativo en nuestro ámbito sociohistórico, se constituyó como institución propositiva con la 
intención no solo de describir las bondades de la nueva tecnología organizativa, sino de pensar en los efectos sobre la sociedad. El pensamiento como institución ejemplificado con un símil más bien automovilístico son como autopistas por donde circulan las relaciones sociales. El pensamiento, no obstante, antecede a la institucionalización de la acción.

No cabe duda de que la construcción de una autopista, de una vía férrea, de una calle, constituye obra estructural no solo por la intencionalidad de permanencia sino porque a través de ellas se circula para llegar a un punto geográfico deseado, pero sin la tarea previa de proyectar sería casi imposible hacer una obra de tal envergadura. Sin dichas obras de ingeniería sería muy difícil organizar la vida cotidiana «racionalmente», entendiendo la racionalidad como sinónimo de economicidad de esfuerzos a la hora de escoger la ruta más idónea para llegar al lugar que se desea. Podríamos afirmar que el pensamiento precede, al igual que un plano arquitectónico, al modelo de sociedad resultante.

El pensamiento organizativo, como eje discursivo, da contenido al modelo social que se pretende instaurar a mediados del siglo xx en España. Aunque no se propone un único modelo, los autores coinciden en la necesidad de un sistema distributivo mucho más equitativo, aplicando las «tecnologías» sociales conocidas con una intención propositiva de cómo se debería construir su modelo de sociedad industrial, basándose en una propuesta técnica cuyo objetivo es superar el conflicto social, que caracterizó la sociedad industrial capitalista de siglo xix y principios del siglo xx. Los autores comparten la ilusión de que la ciencia posee la capacidad de resolución, sea cual sea la índole de la problemática, y es con esta intención que comparten la voluntad de resolver el conflicto social en la nueva sociedad española, que ambiciona desarrollarse bajo criterios de modernidad industrial. A principios del siglo xx nuestra sociedad estaba atenta, como lo está hoy en día, a las innovaciones de cualquier tipo que se daban en nuestro entorno.

No es de extrañar que el método científico de producción de F. W. Taylor y coetáneamente las innovaciones organizativas de Henry Ford fueran conocidos casi de inmediato, como también las propuestas falansterianas que inspiraron el programa económico de determinados partidos y regímenes políticos de inspiración falangista. En una sociedad ciertamente conflictiva, las ánimas más sensibles y cultivadas coincidían en la implantación de los nuevos sistemas organizativos, mediante la aplicación de los sistemas de racionalización del trabajo, pues resolverían «técnicamente» la problemática social entre las clases tradicionales de la sociedad capitalista industrial. La argumentación se fundamentaba en que los incrementos de la productividad, paralela a una disminución de precios, contribuirían a un reparto más equitativo de la riqueza, a través de la adquisición de bienes elaborados mediante el criterio fordista, es decir, la mass-production. 
En consecuencia, la implantación de los nuevos sistemas organizativos ponía al alcance bienes de difícil acceso a la población trabajadora: automóviles, lavadoras, neveras. Dicha circunstancia es lo que se ha convenido en denominar ilusión organizativa - concepto sociológico paralelo al concepto económico de ilusión presupuestaria—, siendo el nervio de la sociedad fordista.

\subsection{Tecnópolis: disrupción entre gasolina y bit}

El apelativo de tecnópolis se circunscribe a una sociedad que organiza su quehacer por el uso intensivo de tecnologías, y habitualmente una de ellas dominante, pues la propia supervivencia de la humanidad se debe por el dominio de una tecnología por simple que sea. El substantivo tecnópolis surge con especial fuerza en la literatura de la sociología económica y de las organizaciones, con la intención de explicar el cambio tecnológico que supone la sustitución de la tecnología analógica por la digital. Uno de los autores que ha reflexionado sobre la temática, Neil Postman, Tecnópoli (1994), la concibe como aquella sociedad que surge por dos innovaciones que significaron una transformación radical de la sociedad: el automóvil propulsado por el motor de ciclo Otto de explosión interna, por un lado, y por otro, la aplicación de los criterios organizativos de Taylor en la cadena móvil de fabricación. Las dos innovaciones crean un binomio que provocará una transformación estructural de la sociedad configurando el modelo social fordista.

Castells (2000; 2006), por su parte, propone la definición de tecnópolis como aquella sociedad que acopla nuevas tecnologías de la información y la comunicación con las incipientes biotecnologías, cuyo impulso de emprendimiento es una combinación de la iniciativa privada, la administración y centros de investigación, tejiendo un cáñamo de alianzas estratégicas cuyos efectos potencian los modelos organizativos basados en la digitalidad. Pero el análisis conceptual aborda un aspecto que se encuentra en la misma definición de tecnópolis y que atañe al concepto de irrupción tecnológica.

En este sentido, Christensen publicó en 1995 «Tecnologías disruptivas: Atrapando la ola», para explicar cómo una tecnología puede modificar de forma súbita la estructura social, es decir, no de manera lenta y progresiva sino de manera irruptora. El ejemplo más paradigmático fue la aplicación de la tecnología organizativa - la cadena de producción - implantada en Ford Motor\&Co. Aunque el objetivo primordial fue poner al alcance de la mayoría de la población el automóvil, el efecto disruptor, de ruptura con la tecnología anterior, conllevó una transformación de las sociedades occidentales sin parangón convirtiendo la industria automovilística durante más de diez lustros en hegemónica y, sobre todo, en una forma de vida. Aunque el automóvil ya estaba inventado antes de su fabricación 
en serie, su disrupción tuvo lugar cuando se infirió a la organización del trabajo la aplicación intensiva, por parte de Henry Ford, de los principios científicos del trabajo de F. W. Taylor, abaratando el precio del automóvil y desarrollando un mercado de masas, cuyo efecto se cristalizó en el modelo de sociedad fordista. Por ello, el concepto de tecnópolis integra en su propia definición la idea de la disrupción, término proveniente de la economía y utilizado en las estrategias de mercado que incorporan la innovación y el desarrollo.

Pero lo más destacado es que en nuestro ámbito analítico nos permite diseccionar los efectos de la aplicación de una tecnología y de poner de manifiesto el proceso de ruptura diacrónica entre tecnologías, pero a la vez nos permite describir el progreso como una disrupción innovadora de carácter continuado que en cierta medida fue expuesta en su día por el economista Schumpeter y el historiador Payson Usher. En síntesis, podemos sostener de todo lo expuesto que la tecnología provoca grandes cambios en la estructura social y que tecnópolis es la sociedad que vive y depende estructuralmente de la tecnología o de tecnologías diversas, habitualmente una de ellas dominante.

En efecto, tecnópolis incluye aquella sociedad industrial basada en el uso intensivo de procesos organizativos taylorizados, uso de energía fósil no renovable, que caracterizó la primera y la segunda revolución industrial - los motores/ calderas de vapor a carbón y posteriormente los motores de explosión interna de petróleo refinado del primer fordismo-, y la nueva sociedad digitalizada de renovables. Dando lugar una revolución tecnológica disruptora que pivota por el proceso de sustitución de lo analógico por lo digital, de lo fósil por lo renovable, de la energía contaminante por las energías limpias con desarrollo paralelo de las nuevas biotecnologías que abarcan el amplio espectro que va de la ingeniería genética aplicada en la industria hasta los procesos estadístico-matemáticos de información recabada por la digitalización como producto de mercado, dando lugar el fenómeno conocido como «bigdata».

Aunque todo ello no excluye un fordismo a nivel global, denominado posfordismo o neofordismo, que habiéndose superado por nuevas formas organizativas —coworking, Hot-desking, walking-meeting, ecosistema colaborativo - refuerza los principios de productividad taylorizada. No cabe duda de que el ADN del propio concepto de tecnópolis incorpora la idea de progreso, y por ello el apelativo no solo se circunscribe en un significado restringido de distrito tecnoindustrial de la enésima revolución tecnológica, sino que da cabida a una visión de amplio espectro de cómo las tecnologías han impactado de manera decisiva en la estructura de la sociedad a lo largo del tiempo. 
De este modo, el término se enriquece cuando incorporamos la perspectiva de más largo recorrido, incluyendo la gran trasformación que supuso el abaratamiento, debido a la producción en cadena del automóvil, dando su acceso a grandes capas de la población. Dicha perspectiva narrativa permite interpretar la «polis» tecnológica a partir de las siguientes variables: la propiedad técnica definida como innovación con potencial de impacto y cambio social; oportunidad de creación y distribución del conocimiento que aporta la nueva tecnología; desarrollo de nuevas habilidades; instituir nuevos procesos organizativos; impacto en la vida cotidiana y el efecto cognitivo consecuente; transformación de las dimensiones interpretativas de espacio y de tiempo. En consecuencia, la tecnología disruptiva edifica un modelo de sociedad en función de la modalidad tecnológica dominante.

\subsection{El texto en su contexto}

El análisis del discurso de la tecnópolis española y su pensamiento organizativo se contextualiza en una realidad, por sí empírica, respecto al origen del fordismo a partir de lo que sucedió con la patente Selden en Estados Unidos. Dicha patente otorgaba el derecho de fabricación y de distribución del motor de gasolina a un determinado número de fabricantes y de distribuidores, convirtiéndoles en una minoría privilegiada oligopolista, pues les otorgaba el derecho de fabricación del motor de explosión interna de ciclo Otto y su venta ante una demanda creciente, comportándoles pingües beneficios. Henry Ford, acompañado por Thomas A. Edison, denunció el uso semimonopolista de la patente ante la justicia. El fallo le fue favorable, pues el juez consideró que tal innovación debía liberalizarse por considerarse una tecnología necesaria para el bien común. Aquella decisión judicial favoreció posteriormente un monopolio natural del mítico Ford T por ser el único automóvil asequible, por el hecho de reorganizar la manera de producirlo aplicando los criterios tayloristas de forma intensiva.

La cadena móvil hizo innecesario que el trabajador se desplazase de una actividad a otra ahorrando tiempo en las operaciones de montaje y aumentando la velocidad de producción, cuyo efecto fue una disminución del precio del automóvil, poniéndolo al alcance de la mayoría trabajadora, hasta entonces solo al alcance de una minoría rica. Ford provocó una disrupción en la estructura social cuyo efecto fue el surgimiento de una burguesía técnica de nuevas clases medias trabajadoras engarzadas a la nueva organización del trabajo. Todo ello conllevó un nuevo modelo de sociedad que se cimentó en una tecnología organizativa, por un lado, y por otro, el automóvil popular, dando lugar al fordismo. Dicho con otras palabras: un invento mecánico complejo, fabricado en serie a partir de la suma de 
actividades simples y repetitivas, dirigido a un mercado mayoritario o de masas, que provocó un reparto ilusorio de la renta sin precedentes.

Hablar de taylorismo en España supone hablar del pensamiento organizativo entre 1900 a 1936. En España el fenómeno del taylorismo y el fordismo fue muy precoz. Se adaptó a una estructura semiartesanal constituida por talleres y fábricas minúsculas de artesanos instruidos y de burgueses ricos con un nivel de conocimientos suficiente para poner en marcha todo un proceso de industrialización tecnológicamente nuevo, resultado de la experiencia y la pericia más que de la experimentación científica. Teniendo en cuenta que la España industriosa del xıx se caracterizó por una clase trabajadora casi analfabeta, ello no fue obstáculo para que determinados sectores innovadores, como fue el del automóvil, tuviesen desde un principio un desarrollo más que notable si se compara con otros países similares.

En España, entre 1880, con el carruaje motorizado de Bonet, y 1940, con el vehículo eléctrico Autarquía, se suman más de cuarenta iniciativas en el sector industrial que será años después protagonista en los planes de desarrollo (Cortés, 2016). Dato que pone en cuestión el subdesarrollo industrial de España respecto a los países del entorno inmediato, sin olvidar el desigual desarrollo de las distintas regiones, no solo entre las españolas sino también a nivel regional europeo. No hay duda de que el nivel de instrucción/formación es una variable explicativa del cambio social en la sociedad. En Madrid y Barcelona entre 1900 y 1930 el analfabetismo se reduce hasta un $13 \%$ y $14 \%$, respectivamente, con una tasa de alfabetización más alta en la villa por su estructura de actividad que atrajo una inmigración más cualificada que la Ciudad Condal, duplicando ambas su población de efectivos demográficos que provenían de las Castillas, que eligen Madrid por su relativa cercanía, y de la cuenca del Ebro y costa mediterránea, en el caso de Barcelona. Un cambio cualitativo importante que conllevó el nuevo proceso reindustrializador, cuyos protagonistas fueron hombres y mujeres conscientes de abrir una nueva etapa en la civilización industrial.

Por este motivo, planificaron nuevas instituciones y renovaron las existentes, para modernizar social, política y económicamente la España del novecientos. La nueva sociedad que va cristalizándose, «taylorista-fordista», es gobernada por una tecnocracia que renueva el aparato productivo y transforma la organización del trabajo. Dicho proceso se traduce en una multiplicación de actividades y especialidades que requiere una nueva función de trabajo que da como resultado un aumento de productividades y abre la revolución organizativa. Revolución que no está dirigida por la burguesía tradicional rentista y fabril, sino por la burocracia técnica de peritos mecánicos y mercantiles, algunas veces por maestros 
ingenieros e intendentes mercantiles, que, sin ser intelectuales en el sentido coloquial, comparten la inquietud política, la cual se manifestará en las formas de autoridad y en las expresiones artísticas. No obstante, lo más notorio del inicio del siglo pasado es la nueva organización, cuyo eje es la prelación distributiva del conocimiento técnico, configurando una nueva clase media que nace por el cambio tecnológico y la nueva organización del trabajo. Un estamento, más que clase social, equipado con las habilidades y la formación para poner en marcha la nueva tecnología que moldeó un nuevo prototipo de ciudadano, híbrido entre político, intelectual y profesional.

\subsection{Los cuatro vértices significativos}

\section{1) Èvvoı $\iota:$ las minorías selectas y la mayoría selecta}

La ennoia ("̌vvoıaı) como imagen inteligible nos introduce un sugerente análisis de cómo las diferentes capas sociales luchan por el dominio y la propiedad de una técnica concreta por medio del discurso. En este nuevo tipo de sociedad, las clases acaecidas dominantes lo son por la capacidad de implantar una tecnología, como fue en su día la pugna entre el gas, la gasolina e incluso aquellos intentos de implantar el motor propulsado por baterías como ocurrió en su momento con el camión Autarquía. El dominio de una técnica sobre la otra privilegia a aquellos que la poseen y obstaculiza la implantación de la tecnología competidora. Sociológicamente afirmamos que cristaliza socialmente una clase tecnócrata que fundamenta su poder por el control de una tecnología determinada; como, por ejemplo, el uso de patentes para la fabricación y la distribución del motor de explosión interna. La tecnología como elemento instrumental en el juego político, la competencia por el poder se resuelve por la capacidad de un grupo entre varios grupos para dominar e implantar una tecnología. Se denomina minoría selecta al grupo ganador $y$, por supuesto, dominante, y mayoría selecta al grupo dominado, pero con capacidad de producción y consumo de los bienes «técnicos», que son propiedad «técnica» de la minoría selecta.

En efecto, la columna vertebral de la tecnópolis se fundamenta en el estudio científico de las aptitudes congénitas y adquiridas de los individuos que componen la mayoría selecta para ubicarlos en la especialidad profesional más acorde al perfil individual en relación con la tecnología dominante. A la vez que se potenciarán centros de formación, los cuales ubicarán científicamente al individuo en relación con sus aptitudes, y las necesidades organizativas (Mira, 1923). Paralelamente, se considerará que la libre elección de la profesión o la reproducción del oficio debido a la influencia de la familia se perciben como variables 
disfuncionales (Tallada, 1927). El objetivo del pensamiento organizativo español fue institucionalizar la racionalidad aplicando los criterios científicos del trabajo para alcanzar el equilibrio social y superar así el conflicto de clases decimonónico.

\section{2) Kaגós: ilusión organizativa}

Las bondades del nuevo sistema y, en paralelo, sus críticas hilvanan el pensamiento organizativo, y a la vez se proponen modelos sociales en relación con los efectos de la racionalización del trabajo. Tanto sus defensores como detractores crearán una ilusión ( $x \alpha \lambda o ́ \varsigma)$, es decir, la ilusión organizativa, como elemento clave para superar la desigual distribución mediante la producción de bienes tecnológicamente

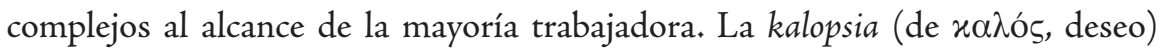
de tecnópolis es superar el egoísmo primitivo, aplicando criterios científicos no solo para la producción (cadena de montaje) y para el consumo (distribución y publicidad) para garantizar la equidad, sino como elemento básico para alcanzar el equilibrio social. El ejemplo por cotidiano se invisibilizó, pero la industria que caracterizó la estructura económica de los últimos cincuenta años del siglo xx se manifestó fordista, dando lugar a una revolución organizativa que permitió abastecer a un mercado de masas de bienes técnicos - coches, lavadoras, neveras, herramientas - induciendo una democratización consumista que empezó con el utilitario 600 de SEAT y el tocadiscos portátil Beltor, cuyo acceso fue debido a un precio relativamente asequible de los inventos del siglo XIX.

La ilusión organizativa fue una revolución manumitida por la férrea disciplina del taylorismo-fordismo donde la gran producción fue el medio para asegurar el retorno de la inversión y alcanzar grandes beneficios, configurando así un capitalismo de carácter nacional. Y previamente el pensamiento organizativo español estudió cómo aplicar y analizar los efectos antes de su instauración como modelo social dominante de la segunda mitad del siglo xx. Hoy aquella realidad industrial, todavía sociológica, ha ido desapareciendo, se ha licuado en cierta medida, cuyos restos materiales e inmateriales se han transformado en muy poco tiempo en piezas arqueológicas. Es decir, la disrupción ha transformado aquella realidad productiva en un fondo de inversión globalizado cuya única razón de ser es la rentabilidad financiera a corto plazo.

\section{3) Aó@ıбтos: aquello que fue}

Dicho planteamiento analítico invita a reflexionar sobre nuestra tecnópolis española y su pensamiento organizativo como modelo social resultante, inmediatamente previo al actual, cuyo relato discursivo tuvo lugar a principios del siglo pasado. No obstante, ya a finales de siglo xıx el capitalismo liberal encuentra 
su máxima expresión en la burocracia fabril, resultado de la articulación de tres tipos de capital: el de los medios de producción, el dinero que los financiaba y la fuerza de trabajo contratada. Tres variables de la función productiva que operaba a nivel local o regional. Ya en el siglo $\mathrm{xx}$ las diferentes innovaciones tecnológicas en el ámbito energético, del transporte, de la comunicación, de los materiales, así como de las nuevas tecnologías organizativas, permitieron una mayor escala de producción de ámbito nacional transformando el capitalismo en organizado en el marco de los Estados de bienestar después de la II Guerra Mundial.

Concretando, desde la sociología de las organizaciones y del trabajo el relato se formaliza en el marco de referencia que de manera tan sugestiva Lash y Urry (1998) definen como capitalismo organizado, reforzando la tesis de Postman (1994), al considerar que el modelo de sociedad del siglo xx es resultado de la aplicación intensiva de los métodos organizativos de Henry Ford, basados en los principios de la organización científica del trabajo propuestos por Taylor años antes de la cadena de producción fordista. Aquella preocupación se manifestó por el interés de la formación laboral como mecanismo de difusión del cambio organizativo y técnico, pero a la vez como propuesta reformadora de la sociedad española, que se institucionalizó en un primer momento en las escuelas del trabajo y, posteriormente, ya en otra etapa de la historia social española, en las universidades laborales.

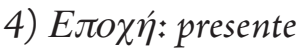

La sociedad industrial y tecnológica de finales del siglo $\mathrm{xx}$ y principios del xxI se halla en un nuevo estadio de desarrollo, progreso y transformación. Los patrones que regían el capitalismo de corte taylorista, pero sobre todo la sociedad organizada bajo los criterios del fordismo, se encuentra en un proceso avanzado de fragmentación. Definido como fordismo difuso y/o global o posfordismo, se manifiesta a igual que una gran cadena de producción ubicada en distintas áreas geográficas funcionales a escala mundial, independientemente de las fronteras tradicionales de los Estados. Siendo el criterio de localización las denominadas ventajas comparativas que presenta cada región/entorno en su dimensión económica y social, a fin de rebajar los costes hasta el mínimo permitido y obtener los máximos beneficios en mercados altamente segmentados en relación con criterios geográficos, demográficos, culturales, políticos y estamento.

El proceso globalizador coincide con el inicio de la crisis de 1973, revalidado por las políticas económicas monetarias de corte neoliberal defendidas por la Escuela de Chicago y representadas por el economista Milton Friedman, reafirmándose en los Gobiernos de Margaret Thatcher en 1979 en el Reino Unido 
y Ronald Reagan en Estados Unidos a partir de 1981. Etapa que también se denomina de capitalismo tardío o capitalismo desorganizado, a consecuencia de las políticas de desregulación del Estado de bienestar por parte de los Gobiernos conservadores, sobre todo del área angloamericana, que marcarán el rumbo de la economía mundial abandonando las tesis keynesianas y sustituyéndolas por la política de corte monetarista. Se inaugura así el neoliberalismo económico a imitar por el resto de las economías del mundo desarrollado, dando un paso más en la intensificación de la flexibilidad productiva que caracteriza al posfordismo.

En consecuencia, se desarticula la relación entre capital y trabajo del capitalismo organizado y del mismo fordismo como efecto directo de la nueva arquitectura organizativa que se implanta por la traducción de cualquier proceso comunicativo/organizativo en lenguaje informático, virtualizando las dimensiones espacio/temporal de la industria fordista, extirpándole la ubicación y extrayendo la temporalidad. Si aquel capitalismo organizado y analógico afianzó productividades y permitió acumulaciones, hoy la virtualización organizativa del «capitalismo informacional» (Castells, 2000; 2006) permite incrementos exponenciales de productividad y acumulación, fortaleciendo la esencia misma del capitalismo. El nuevo paradigma tecnoeconómico del informacionalismo ha provocado una aceleración de la redistribución espacial, abriendo, en términos neoclásicos, «un mundo de competencia cuasi-perfecta y, por tanto, un mercado más eficaz, más ágil y generador de valor, pero al mismo tiempo agresivo y exigente» (Brunet y Bocker, 2013: 139).

Un mundo en el que «la protección institucionalizada y garantizada por el Estado ha quedado expuesta a los caprichos de un mercado que ha acabado por convertirse en terreno de juego de fuerzas globales al margen del alcance del control político» (Bericat, 2019: 170). Un mundo en el que los empleos permanentes, seguros y garantizados del fordismo son una excepción, un privilegio reservado a unos pocos, aunque ni siquiera esos pocos puedan gozar de una total seguridad (Bauman, 2000). Un mundo «que se ha convertido en un laberinto de puestos de trabajo fragmentarios» (Sennett, 2013:27), de pobres que trabajan (Bauman, 2011). De hecho, después de definir el nuevo capitalismo como un régimen de poder ilegible, Sennett (2006) llega a la conclusión de que la pérdida del empleo ha dejado de ser un problema exclusivo de la clase obrera.

En definitiva, el posfordismo o neofordismo ( $\mathrm{el}$ neofordismo al igual que el fordismo, se basa en un principio de organización de las fuerzas productivas sujetas a las exigencias de la dirección capitalista. El neofordismo representa las relaciones de producción capitalistas todavía en gestación, con objeto de responder a la crisis de la reproducción de la relación salarial a fin de salvaguardar el 
capitalismo», Aglietta, 1979: 99), como fenómeno organizativo de la nueva era del capitalismo, tiene su correlato en la posmodernidad consumista, expresándose como el desplome de valores y de significados, inhabilitando de pleno el valor trabajo como dispositivo de proyecto personal mayoritario y mecanismo de movilidad social. De hecho, la sustitución de los medios para llegar a un fin no supone el cambio de los objetivos tal como afirmó en su día Weber y demuestra obstinadamente la historia. Pero, en la actual historia, «la justicia del mercado también implica estándares normativos — los de los propietarios y administradores del capital- pero en este sentido es justicia social que se presentaría con la ayuda de la teoría económica estándar, más bien como justicia natural que como justicia social» (Streeck, 2016:68).

\section{Conclusión}

Boltanski y Chiapello (2002: 60) sitúan en el centro de sus análisis las ideologías sobre las cuales descansa el capitalismo, al ser de vital importancia para el capitalismo apoyarse «en un aparato justificativo y ajustado a las formas concretas adoptadas por la acumulación del capital en una época determinada». Pues bien, el discurso sobre la tecnópolis constituye toda una serie de representaciones y de justificaciones compartidas acerca del fordismo, y es que sin ideología la persistencia «del capitalismo como modo de coordinación de las acciones y modo de vida no podría ser comprendida» (Bericat, 2019: 150).

En este sentido, la tecnópolis en España se inscribe en su pensamiento organizativo, netamente justificativo, que se desarrolló a inicios del siglo xx, cristalizándose posteriormente su mayoría selecta. Aleccionándonos en Max Weber (1864-1920), tecnópolis es un discurso de carácter mesocrático, de clase media o capas sociales que se definen como medias, descritas como estratos (en el sentido más geológico del término) propietarias de pequeña o media propiedad, adquirida mediante el mecanismo distributivo del mercado de masas, y aptitudes cognitivas necesarias para garantizar el funcionamiento de la tecnología dominante, aprendidas en el sistema educativo y que comparten el universo simbólico de las clases propietarias y dominantes.

El término tecnópolis define una sociedad que depende y a la vez se fundamenta en la tecnología. La técnica como institución social no se debe entender solo como un proceso mecánico de actividades y medios para llegar a un fin, sino, tal y como refiere su raíz etimológica, una sociedad que piensa y trabaja para y con la técnica. La sustitución del modo de producción, en el sentido marxista, y su transformación consecuente de la estratificación social, en la dirección weberiana del concepto, configura la mayoría selecta, siendo su pensamiento or- 
ganizativo el discurso que expresa el proceso de cambio que se avecina de una sociedad fabril, de economías de pequeña escala a otra industrial a gran escala de producción. Sin embargo, la peculiaridad se ciñe en la necesidad de construir un nuevo modelo de trabajador entre operario de gran fábrica y especializado en alguna de las últimas técnicas.

El cambio de paradigma productivo de la pequeña organización semiartesanal a la gran organización industrial exigió la implementación de una política educativa - escuelas del trabajo, universidades laborales - para viabilizar no solo la rentabilidad económica de las inversiones, sino para afianzar simultáneamente el nuevo modelo de sociedad de tintes mesocráticos e incluso de aromas conservadores. Cuyo modelo social no se delimita exclusivamente a la aplicación de la tecnología y sus efectos organizativos, que también, sino a un relato no manifiesto propio del pensamiento organizativo cuyos cantos de sirenas se dirigen a aquellas clases sociales que no son propietarias ni proletarias, ubicándose en la escala social por su capacidad de uso y novación sobre una determinada técnica.

La reproducción de la desigualdad social, pues, no es el resultado exclusivamente de la propiedad de los medios sino de los mecanismos a partir de los cuales se distribuye el conocimiento, incentivando la innovación y el cambio social. Tecnópolis se asienta en dicha ley sociológica cristalizándose en el pensamiento organizativo español, cuya sképsis se centró en el qué, el cómo, el cuándo y el porqué de la incorporación de una nueva tecnología organizativa y sus efectos en la sociedad.

Para concluir, la tecnópolis consciente del nuevo orden social gravitó en la gran industria fordista cimentada en la organización científica del trabajo de Taylor, ilusionando a una mayoría cuya propia autoimagen de selecta, évvoı $\iota$, lo fue por su capacidad de compra en los mercados masas cuyo k $\alpha \lambda$ ó $\varsigma$ fue traducido mediante la «democratización» del consumo. 


\section{Bibliografía}

Aglietta, Michel (1979). Regulación y crisis del capitalismo. Madrid: Siglo XXI. Babbie, Earl (2000). Fundamentos de investigación social. Madrid: Thomson.

Baudrillard, Jean (2010). Crítica de la economía política del signo. Barcelona: Anagrama.

Baudrillard, Jean (2012), La sociedad de consumo. Sus mitos, sus estructuras. Madrid: Siglo XXI.

Bauman, Zygmunt (2000). Trabajo, consumismo y nuevos pobres. Barcelona: Gedisa.

Bauman, Zygmunt (2011). Memorias de clase. La prebistoria y la sobrevida de las clases. Buenos Aires: Nueva Visión.

Bericat, Carmen (2019). La transformación de las relaciones laborales. Fundamentos teóricos de un proceso de cambio. Zaragoza: Prensas de la Universidad de Zaragoza.

Boltanski, Louis y Chiapello, Eve (2002) El nuevo espíritu del capitalismo. Madrid: Akal.

Brunet, Ignasi y Pastor, Inma (1997). Educación, trabajo y género. Barcelona: Llibreria Universitària de Barcelona.

Brunet, Ignasi y Morell, Antonio (1998). Clases, educación y trabajo. Madrid: Trotta.

Brunet, Ignasi y Pastor, Inma (2003). Ciencia, economía y sociedad. Madrid: Fundamentos.

Brunet, Ignasi; Belzunugui, Ángel y Pastor, Inma (2002). Tecniques d'investigació social. Fundaments epistemològics i metodológics. Barcelona: Pòrtic.

Brunet, Ignasi y Bocker, Rafael (2013). Capitalismo global. Aspectos sociológicos. Madrid: Grupo 5.

Brunet, Ignasi; Pizzi, Alejandro y Moral, David (2016). Sistemas laborales comparados. Las transformaciones de las relaciones de empleo en era neoliberal. Madrid: Ediciones Universidad Nacional del Litoral-Anthropos.

Brunet, Ignasi; Pizzi, Alejandro y Moral, David (2019). Industrial relations and finantial globalization. Tarragona/Valencia: Publicacions URV/PUV. Universitat de València.

Castells, Manuel (2000). La era de la información. Madrid: Alianza.

Castells, Manuel (2006). La sociedad red. Madrid: Alianza.

Corbetta, Piergiorgio (2003). Metodología y técnicas de investigación social. Madrid: McGraw-Hill.

Corominas Montañá, Pedro (1975). El Contrato Social y La Era de la Organización (1930). Madrid: Gredos. 
Cortés, José M. a (2008). Discurs de la racionalització del treball a Catalunya durant l'era de l'organització, 1900-1936. Tarragona: Universitat Rovira i Virgili, Departament de Gestió d'Empreses (Tesis doctoral).

Cortés, José M.* (2009). «Propuestas para una sociedad tecnopólica en el Pensamiento Organizativo español. Igualdad, desarrollo y cooperación». XIV Congreso nacional de Sociología en Castilla-La Mancha. Toledo, Centro de Iniciativas de Cooperación al Desarrollo (Universidad de Alcalá) y Asociación de Castellanomanchega de Sociología.

Cortés, José M+ (2012). La Tecnópolis catalana, el Pensament Organitzatiu a Catalunya, 1900-1936. Tarragona: Edicions URV.

Cortés, José M+ (2016). La Majoria Selecta de la Tecnópolis Catalana, 19401980. Tarragona: Edicions URV.

Christensen, Clayton M. y Bower, Joseph L. (1995). «Disruptive Technologies: Catching the wave». Harvard Business Review, 73(1).

De la Garza, Enrique (2006). Teorías sociales y los estudios laborales. Barcelona: Anthropos.

Federici, Silvia (2018). El patriarcado del salario. Críticas feministas al marxismo. Madrid: Traficantes de sueños.

Ford, Henry (1931a). Hoy y mañana. Madrid: M. Aguilar Editor [escrito en 1926 en colaboración con Samuel Crowther].

Ford, Henry (1931b). Progreso. Madrid [escrito en 1926 en colaboración con Samuel Crowther].

Foucault, Michel (2012). Vigilar y castigar. Nacimiento de la prisión. Madrid: Siglo XXI.

Granier-Barrera, Emilio (1947). La Cultura Nacional de Catalunya. México: Catalunya, VII, No. 131.

IвÁÑez, Jesús (1985). Del algoritmo al sujeto. Nuevas perspectivas de la investigación social. Madrid: Siglo XXI.

Imaz, Eugenio (1979). El Pensamiento de Dilthey. México: Fondo de Cultura Económica.

Lamo de Espinosa, Emilio (1990). La Mirada reflexiva (sujeto y objeto del conocimiento). Madrid: CIS/Siglo XXI.

LAsh, Scott y Urry, John (1987). The end of organized capitalism. Madison: University of Wisconsin Press.

LASH, Scott y URRY, John (1998). Economías de signos y espacio: sobre el capitalismo de la posorganización. Buenos Aires: Amorrortu. 
Mallart Cutó, José (1932) La organización cientifica del trabajo en España. Madrid: Huelves y Cía., s. a. [1932?, Asociación Española para el Progreso de las Ciencias, sesión del 17 de mayo de 1932].

Mira López, Emilio (1965). Manual de Orientación profesional (6. a ed.). Buenos Aires: Ed. Kapelusz.

Montoliu Togores, Cipriano (1916). El sistema de Taylor y su crítica. Barcelona: Casa Editorial Estudio.

Oriol Anguerra, Antonio. (1938). Conceptes 1939. Assaigs. Barcelona: Atenea.

Payson Usher, Abbott (1955). A History of Mechanical Inventions. Isis Volume: 46 Issue 3, ISSN: 0021-1753 Online ISSN: 1545-6994.

Picó, Joan (1988). Modernidad y postmodernidad. Madrid: Alianza.

Postman, Neil (1994). Técnopolis. Barcelona: Llibres de l'Índex (Col.lecció Els Senyals, 4).

Rius Sintes, Isidro (1950). Organización industrial. Barcelona: Casa editorial Bosch.

Roca Rosell, Francesc (1998), La Ciutat tayloritzada i la seva crítica. Barcelona: Vida obrera en la Barcelona de entreguerras 1918-1936. Barcelona: Centre de Cultura Contemporània de Barcelona.

Roca Rosell, Francesc (2000). Teories de Catalunya. Guía de la societat contemporània. Barcelona: Ed. Pòrtic.

Ruíz Almansa, Javier (1928). «La política de racionalización en las naciones modernas». Revista de Organización Cientifica, 1(2).

Ruíz Almansa, Javier (1929). Manual Práctico de Organización Cientifica del Trabajo. Barcelona: Editorial Cultura.

Ruíz Almans a, Javier (1947). «Crítica y noticias de libros, Viaje a Simancas en busca del catastro del marqués de la Ensenada», $A B C, 30$ de enero de 1947.

Ruíz Castella, José (1921). L'escola primària i l'orientació professional: conferencia. Institut d'Orientació Professional. Publicacions de l'Institut d'Orientació Professional. V. 3.

Ruíz Olabuenaga, José (1996). Metodología de la investigación cualitativa. Bilbao: Deusto.

Sampedro Sáez, José Luis (2009). Economía Humanista, algo más que cifras. Barcelona: Debate.

Sánchez Capdequí, Celso (2017). «La creatividad social: narrativa de un concepto actual». Madrid: Centro de Investigaciones Sociológicas.

Sassen, Saskia (2007). Una sociología de la globalización. Madrid: Katz. 
Shumpeter, Joseph Alois y Hans Lederer, Emil (2015). "Capitalist development, innovations, business cycles and unemployment». Journal of Evolutionary Economics. 25(1): 117-138.

Sennett, Richard (2006). La cultura del nuevo capitalismo. Barcelona: Anagrama.

Sennett, Richard (2013). Artesanía, tecnología y nuevas formas de trabajo. Barcelona: CCCB/Katz.

Streeck, Wolfgang (2016). Comprando tiempo. La crisis pospuesta del capitalismo democrático. Zaragoza: Katz.

Tallada Paulí, José María (1922). L'organització cientifica del treball. Barcelona. Publicacions de l'Intitut d'Orientació Professional. V. 3.

VAllés, Miguel S. (1996). Técnicas cualitativas de investigación social. Madrid: Síntesis.

Weber, Max (1922). Economía y Sociedad. México, DF.: Fondo de Cultura Económica.

Weber, Max (1981). Ensayos metodológicos. Barcelonaः Península. 